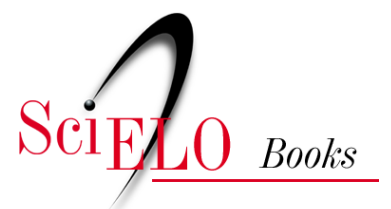

\title{
7. Ambiente de informação em saúde na gestão estadual do SUS
}

\author{
Ilara Hämmerli Sozzi de Moraes \\ Miguel Murat Vasconcellos
}

\section{SciELO Books / SciELO Livros / SciELO Libros}

MORAES, I.H.S., and VASCONCELLOS, M.M. Ambiente de informação em saúde na gestão estadual do SUS. In: UGÁ, M.A.D., et al., (orgs.). A gestão do SUS no âmbito estadual: o caso do Rio de Janeiro [online]. Rio de Janeiro: Editora FIOCRUZ, 2010, pp. 169-194. ISBN: 978-85-7541-592-4. Available from: doi: $10.7476 / 9788575415924.0009$. Also available in ePUB from: http://books.scielo.org/id/c2hxb/epub/uga-9788575415924.epub.

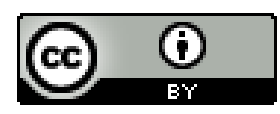

All the contents of this work, except where otherwise noted, is licensed under a Creative Commons Attribution 4.0 International license.

Todo o conteúdo deste trabalho, exceto quando houver ressalva, é publicado sob a licença Creative Commons Atribição 4.0. 


\title{
Ambiente de Informação em Saúde na Gestão Estadual do SUS ${ }^{1}$
}

\author{
Ilara Hämmerli Sozzi de Moraes \\ Miguel Murat Vasconcellos
}

[Em Espinosa] A virtude da alma é conhecer (...) Ela é ativa quando o conhecimento depende dela própria, de sua força própria - é ativa na razão. É ativa quando consegue compreender a ordem e conexão necessária do real, a produção do real e a inserção do homem nessa produção.

Marilena Chauí

\section{CONTEXTUALIZAÇÃO: AÇÕES INFORMACIONAIS E SUA INCORPORAÇÃO NA GESTÃO DA SAÚDE}

\begin{abstract}
A informação e a tecnologia de informação (TI) constituem uma das áreas de desenvolvimento tecnológico, metodológico e teórico de crescente importância política, econômica e de inovação (Levy, 1993; Castells, 1999; Gómez, 2001). São percebidas pela sociedade como força motriz para aumento de produtividade de bens e de serviços e para geração de novas informações, em uma espiral contínua. A depender da concepção adotada, a informação é social e politicamente interpretada como 'recurso que agrega valor' a bens e serviços, sendo apresentada como 'despolitizada'. Esse significado ancora-se em formulações neoliberais que, se não negam, minimizam, implícita ou explicitamente, as dimensões política, econômica e social presentes desde sua matriz genealógica. De um modo geral, ressalta-se apenas a dimensão que aparece como desenvolvimento de ciência e tecnologia a ser incorporado em processos e produtos. Entretanto, na contemporaneidade, a informação e a TI configuram-se como resultantes do entrechoque de interesses econômicos, políticos, sociais e da ciência e tecnologia, ao mesmo tempo que participam estruturalmente da formação histórica das sociedades (Chauí, 1997).

No Brasil, a apropriação dos possíveis benefícios da informação e da TI para o Sistema Único de Saúde (SUS) ocorre de forma atomizada, espasmódica, em contextos de relações de poder e de produção de saber, inerentes a processos decisórios de políticas públicas, sem uma ampla discussão nas instâncias do SUS sobre as opções políticas e tecnológicas adotadas (Gómez, 2001; Moraes, 2002; Vasconcellos, Gribel \& Moraes, 2008). Este quadro agrava a defasagem existente na incorporação de ações informacionais
\end{abstract}

\footnotetext{
${ }^{1}$ Agradeço a Clarisse Hämmerli, Silvia Rangel e Vanessa Lima pela generosidade e paciência de revisarem o texto original.
} 
na gestão em saúde, com embates de interesses e concepções em torno do modelo de gestão da informação.

O tema é analisado por diferentes autores (Levy, 1993; Castells, 1999; Gómez, 2001; Moraes \& Gómez, 2007; Dunley, 2005) que sinalizam a persistência de um contexto onde coexistem 'antigos' problemas, decorrentes da gênese e da história de sua matriz constitutiva, com 'novos' problemas, que emergem pari passu ao dinamismo das práticas e dos saberes informacionais no mundo atual.

Moraes e Gómez (2007) colaboram para a compreensão da complexidade crescente deste contexto ao desenvolverem o entendimento de que as ações informacionais em saúde ${ }^{2}$ constituem um dos dispositivos de Estado nas sociedades contemporâneas que

- repercutem nos modos de vida de indivíduos e coletivos, influenciando os sentidos e significados do binômio saúde/doença;

- tornam-se um dos fundamentos essenciais ao próprio processo de gestão em saúde;

- são instituídos na práxis em saúde, ao mesmo tempo que são um dos instituintes do processo de trabalho, tornando-se, então, o eixo principal para o desenvolvimento e a implementação de novas práticas e conhecimentos informacionais;

- constituem-se em espaços de relações de poder e de produção de saber, onde poder e saber são faces de uma mesma moeda.

Tendo por referência este entendimento de ações informacionais em saúde e os estudos citados, delineia-se um panorama dos principais problemas encontrados no contexto atual da informação e TI em saúde no Brasil:

- Ausência de uma 'cultura de informação' que fomente a constituição de ambiente de informação voltado para seu uso na gestão em saúde e nos processos decisórios.

- Elaboração de sistemas de informação em saúde (SIS) que funcionam sem interoperabilidade ('não se falam').

- Fragilidade na implementação de mecanismos contínuos de avaliação da qualidade da informação em saúde.

- Fraca identidade das práticas e dos saberes relacionados à gestão da informação e informática (TI) em saúde nas estruturas organizacionais, que se apresentam dispersas e descoordenadas, com pouca valorização deste processo de trabalho.

- Visão reducionista e tecnicista, de 'área meio', tornando-se opaca sua função estratégica, favorecendo a justificativa para sua terceirização.

- Quase inexistência de formação permanente da equipe de informação e TI em saúde.

\footnotetext{
2 Para efeito deste trabalho, considera-se como 'ações informacionais em saúde' aquelas que ocorrem na práxis da atenção em saúde relacionadas ao processo de gestão, produção, desenvolvimento, processamento, tratamento, análise, controle e avaliação das informações e das tecnologias que lhes dão sustentação.
} 
- Forte pressão das empresas de informática em disputa pelo mercado 'da saúde'.

- Insuficiência de investimentos para estruturar a área de informação e suas tecnologias em iniciativas estratégicas para o SUS, como identificação unívoca do indivíduo e prontuário eletrônico, com o sucateamento de suas instâncias públicas de gestão.

- Alta vulnerabilidade a riscos na preservação da privacidade e da confidencialidade de informações em saúde, mormente com identificação nominal dos usuários do SUS.

- Linguagem inadequada na disponibilidade das informações, dificultando seu processo de apropriação pelos conselhos de saúde (CS) e pela população em geral.

- Gestão da 'informação' desvinculada da gerência de Informática/TI em grande parte das estruturas organizacionais das instituições em saúde das três esferas de governo.

Apesar do impacto representado pelo avanço da microcibernética, mantém-se um modelo organizacional herdado das décadas de 1980 e 1990, quando da existência de mainframes e dos Centros de Processamento de Dados (CPD), que reforça a dicotomia entre 'informação' e 'tecnologia de informação', beneficiando apenas o modelo de terceirização deste campo.

A quem interessa a manutenção desse status quo informacional na saúde? Por que é tão difícil a construção de mudanças nessa área? Quais as condições materiais, econômicas e políticas que contribuem ou dificultam a construção de avanços nesse processo? Responder a essas questões tem diferentes caminhos, trilhados por diversos sujeitos históricos em seus espaços de atuação. Longe de pretender respondê-las, objetiva-se neste capítulo aprofundar a compreensão sobre o processo de incorporação das ações informacionais na gestão do SUS, tendo por referência a gestão estadual, procurando extrair subsídios que orientem a constituição de ambiente de informações em saúde voltado para o uso intensivo da informação e de suas tecnologias no processo decisório em saúde.

Para tal, analisa-se o processo de incorporação das ações informacionais na gestão do SUS no estado do Rio de Janeiro (ERJ), entre 1999 a 2006, no decorrer da iniciativa de aplicação do modelo, desenvolvido por Vasconcellos, ${ }^{3}$ de Ambiente de Informações para Apoio à Decisão em Saúde (AmIS), articulado à implementação da regulação assistencial. O período longo de estudo (oito anos) foi considerado necessário para a obtenção de subsídios que orientem o aperfeiçoamento da forma original do modelo, discutindo sua validade em duas dimensões:

- Contribuiu para uma gestão direcionada à incorporação das ações informacionais nos processos decisórios em saúde?

- Forneceu subsídios para o aprimoramento do modelo original de AmIS, colaborando para a melhoria de sua aplicação em outras iniciativas de gestão estadual no SUS?

\footnotetext{
3 O modelo foi desenvolvido por Miguel Murat Vasconcellos, mas publicado em artigo que envolvem outros autores. Ver Vasconcellos, Moraes \& Cavalcante (2002).
} 
As ações informacionais em saúde constituem o objeto da pesquisa em torno do qual se desenvolve investigação avaliativa por triangulação de métodos (Minayo, Assis \& Souza, 2005). Adota-se uma abordagem quantitativa e qualitativa, em um trabalho cooperativo (entre instituição de pesquisa e pesquisados) e interdisciplinar, de estudo seccional. Na abordagem quantitativa, utiliza-se desenho quase-experimental e por séries temporais. Já na abordagem qualitativa, aplica-se desenho hermenêutico-dialético buscando uma avaliação ao mesmo tempo compreensiva e crítica.

Dentre o conjunto do material utilizado, cabe destacar:

- Estudos documentais de portarias, resoluções e atas de reuniões:

- Na esfera federal: da Comissão Intergestores Tripartite (CIT); do Comitê Tripartite de Informação e Informática em Saúde da CIT; da Câmara Técnica de Informação e Informática do Conselho Nacional de Secretários de Saúde (Conass), incluindo suas notas técnicas; do Conselho Nacional de Secretários Municipais de Saúde (Conasems) e do Ministério da Saúde, com destaque para sua Secretaria de Ações de Saúde, no que se refere ao arcabouço jurídico institucional da regulação assistencial (SES/RJ).

- Na esfera estadual: da Comissão Intergestores Bipartite (CIB), do Conselho Estadual de Secretários Municipais de Saúde (Cosems) e da Secretaria de Estado de Saúde.

- Estudos estatísticos da produção da Rede de Centrais de Regulação/RJ, a partir das seguintes fontes: Sistema de Informação de Mortalidade (SIM), Sistema de Informação de Nascidos Vivos (Sinasc), Sistema de Informação Hospitalar (SIH/ SUS), Sistema de Informação Ambulatorial/Autorização de procedimentos de alta complexidade/custo (Apac)/(SIA/SUS) e Sistema de Informação de Regulação (Sisreg/Datasus).

- Relatório de campo elaborado a partir de observação participante realizada por pesquisadores do Grupo de Pesquisa/CNPq Informação e Saúde da Escola Nacional de Saúde Pública Sergio Arouca da Fundação Oswaldo Cruz (Ensp/Fiocruz).

- Relatórios técnicos elaborados em função de visitas de acompanhamento do funcionamento das centrais de regulação regionais, a cada três meses, por oito horas, em rodízio, de 2003 a 2006.

A análise do conjunto deste material, à luz dos marcos referenciais que fornecem sustentação ao modelo de AmIS, fundamenta os resultados desta investigação. Espera-se, desse modo, aliar-se aos esforços coletivos de construção de práticas e saberes colocados a serviço da superação de problemas do SUS no ERJ e com isso extrair lições que contribuam para inovações na gestão das ações informacionais em saúde no âmbito da gestão do SUS no país. 


\section{Breve Apresentação do Modelo de Ambiente de Informações em SAÚDE - AMIS}

O AmIS constitui um dos resultados do Grupo de Pesquisa/CNPq Informação e Saúde da Ensp/Fiocruz, mais especificamente a partir do desenvolvimento das pesquisas “'Desenvolvimento de sistema de informação para apoio à decisão em saúde” e "Uso da tecnologia de informação em saúde em processos regulatórios”. Proposto por Miguel Murat Vasconcellos, foi publicado em 2002 (Vasconcellos, Moraes \& Cavalcante, 2002) e desenvolvido com a preocupação de sua aplicabilidade em situações concretas, como contribuição à atenção em saúde, ao ser incorporado como integrante do processo de trabalho em saúde.

O Ambiente de Informações para Apoio à Decisão em Saúde (aqui denominado simplesmente AmIS) implica uma concepção de organização das informações em saúde propícia ao estabelecimento de uma sinergia de competências, recursos e memórias, frutos e matrizes do conhecimento em saúde, coletivamente produzido por seus sujeitos históricos. Vincula-se ao conceito de 'intercampo da informação em saúde', conforme descrito por Moraes e Gómez (2007), ao pressupor um modus operandi de interação e cooperação ágeis e transversais, em um compartilhamento coordenado entre centros de decisão distribuídos pelo sistema e serviços de saúde, compondo uma infocontextura que tece objetivamente uma 'rede de saúde', contribuindo para um sistema integrado de serviços, ações e informações em saúde.

Configuram-se, assim, no tempo e espaço cibernético, possibilidades de alcance de níveis de complexidade crescente no desenvolvimento de alternativas para a melhoria da função gestora em saúde, com repercussões na capacidade de governança das autoridades sanitárias e de melhoria da qualidade da atenção à saúde. Essa perspectiva delimita o espectro de atuação do AmIS que tem, como esfera de intervenção, tanto a consciência subjetiva quanto o interesse prático, ao se tornar operador de ações clínicas, administrativas, gerenciais, tecnocientíficas e política-econômica-sociais. Ou seja, consubstancia-se em função essencial da gestão pública em saúde.

Destaca-se que o AmIS, virtual por excelência, está imerso no 'mundo da saúde' e no 'mundo da política', expressões simplificadoras, representadas, na Figura 1, pelo simbolismo de 'nuvens'. Uma rápida leitura da figura evidencia a necessidade de intensa circulação entre campos de saber (por exemplo, modelagem espacial, estatística e matemática), pressupondo uma abordagem interdisciplinar e transdisciplinar, em um processo gradual para sua aplicação.

Observa-se também a preocupação de Miguel Murat Vasconcellos em incluir na modelagem do AmIS funcionalidades que garantam aderência ao conceito de rede assistencial regionalizada e hierarquizada, onde seja possível recuperar as informações por critérios geográficos, pelo perfil de complexidade das unidades assistenciais, pelo fluxo de acessibilidade dos pacientes, prevalência e incidência dos agravos, articulando-as no tempo e espaço. Essa gestão da informação amplia as possibilidades de uso do ambiente 
de informações em saúde, subsidiando a otimização dos recursos e a produção coletiva de inovações no SUS (Campos, 2007).

Na modelagem do AmIS, é condição sine qua non o debate contínuo com os envolvidos. Este requisito fundamenta-se no entendimento de que participar confere o estatuto de coautoria e corresponsabilidade com a proposta, tendo por imagem-objetivo a constituição de uma 'tecnodemocracia' (Levy, 1993). O AmIS precisa ser incluído na pauta dos espaços colegiados instituídos no SUS, sob pena de frustrar a vocação de fomentar sua incorporação nos processos decisórios da saúde, ficando confinado a abordagens tecnicistas e tecnocráticas (Ver Figura 1).

O AmIS, nos moldes em que foi desenvolvido, é forjado 'com' ele ('sujeito informacional') e não 'para' ele. Essa forma de estruturação fortalece a inserção do AmIS na práxis em saúde como macrofunção estratégica de sua gestão como dispositivo político de um Estado democrático. Essa concepção de gerir a informação procura atender ao desafio de ampliar seu uso no cotidiano do processo decisório da saúde seja na formulação de políticas, na gestão, nas vigilâncias, na clínica, seja no controle social. Tal desenho tem como pré-requisito adotar o processo de trabalho em saúde como a matriz de referência para a organização das informações e tecnologias, dentro da qual o prontuário estruturado do paciente é o núcleo central.

Delineia-se, assim, no tempo e espaço cibernéticos, um aqui/agora fértil à produção de uma inteligência coletiva que tenha por compromisso a (re)construção da 'atualidade' (Kant, 1996) do setor saúde. Ancorado na intersetorialidade e na transdisciplinaridade (Almeida-Filho, 2005), o AmIS se estrutura a partir de uma dinâmica que articula processos políticos de busca de consensos, ao mesmo tempo que induz intensa circulação comunicativa entre campos de saberes, destacando-se: ciências da saúde, ciências da computação, ciências humanas e sociais, ciência política, ciência matemática e as engenharias de produção, telecomunicação e biomédica.

\section{Gestão de Ações Informacionais em Saúde e Regulação Assistencial na Esfera Estadual: estado do Rio de Janeiro}

A implementação de experiências de adoção de ambiente de informação em saúde em espaços concretos do SUS constitui importante fonte de análise e avaliação sobre seu potencial de aplicação. Dessas iniciativas, investiga-se a experiência da SES/RJ, coordenada por seu Centro de Informações em Saúde (Cisa).

A seleção do estado do Rio de Janeiro para o estudo deve-se à permanência de uma única gestão da SES/RJ por duas legislaturas: 1999 a 2006, com intervalo de nove meses, de março a dezembro de 2002. Este critério é importante por minimizar a interveniência de fatores decorrentes de contínuas mudanças em um staff diretivo que se manteve sob a direção de Gilson Cantarino, propiciando uma análise de longo prazo. Três outros critérios foram considerados também: 1ํ inclusão, na agenda de prioridades do SUS, da melhoria da qualidade das informações em saúde e do fomento ao seu uso na gestão da 


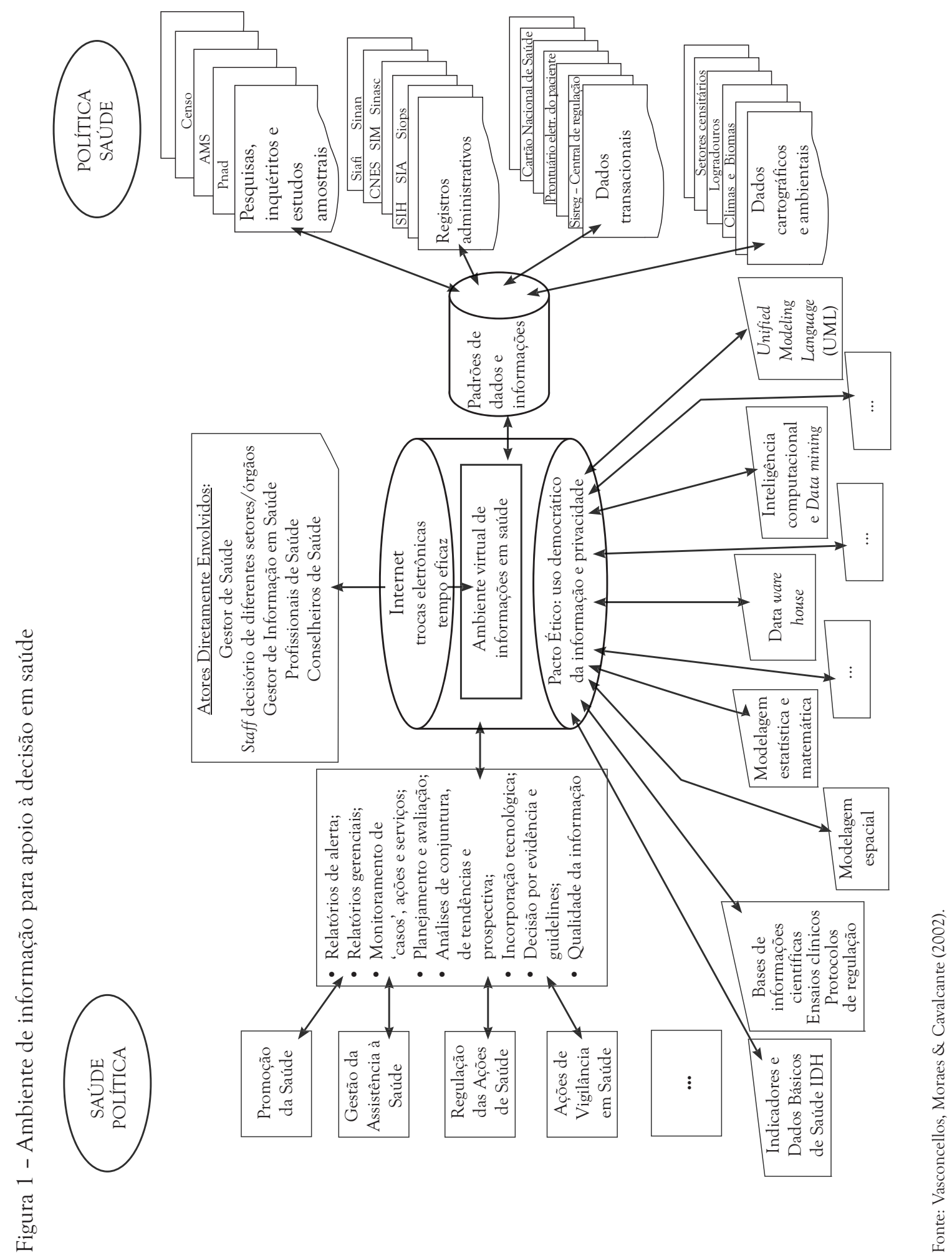


saúde; 2ํ decisão de implementar regulação assistencial em saúde que, no fim dos anos 90, apresenta-se como um campo em estruturação, contribuindo para análise de um processo de incorporação de ações informacionais; e 3 o opção por aplicar um modelo de ambiente de informações em saúde específico (AmIS), em um trabalho conjunto com instituição de ensino e pesquisa (Ensp), propiciando um ambiente fecundo para desenvolvimento de inovações metodológicas e tecnológicas.

O recorte analítico estabelece como foco da investigação as ações informacionais, desenvolvidas pelo Cisa/SES-RJ de 1999 a 2006, associadas à aplicação do modelo AmIS e vinculadas à implantação da regulação assistencial no ERJ. Para facilitar a compreensão do contexto dessa análise, faz-se necessária uma breve descrição de seus oito anos.

Esta experiência possui um modus faciendi complexo por pressupor articular desenvolvimento tecnológico e inovação de práticas em gestão clínica, gestão de ações informacionais e regulação assistencial, envolvendo as três esferas de governo. Sua implementação pode ser caracterizada em duas etapas: de janeiro de 1999 a março de 2002 e de janeiro de 2003 a dezembro de 2006.

Em 1999, quando os primeiros passos dessa iniciativa foram dados, a construção do pensamento brasileiro em torno do tema 'regulação assistencial' estava em sua fase embrionária, com poucas referências normativas e bibliográficas, conferindo, na época, um caráter de pioneirismo e inovação à experiência. A etapa inicia-se com intenso debate, principalmente entre os componentes da CIB/RJ em torno dos pilares organizativos da proposta, aprovados pela deliberação CIB/RJ n. 39 de 24 de junho de 1999 (Estado do Rio de Janeiro, 1999). Esta define que implementar a regulação assistencial é prioridade, incluindo em seu escopo a organização de uma Rede de Centrais de Regulação (RCR) como componente estratégico do complexo regulador, tendo como base o desenvolvimento de uma Rede de Informação ('infocontextura').

O diagnóstico da situação de saúde, elaborado à época por assessores do secretário de estado, conclui que o principal ponto de estrangulamento na rede assistencial persistia sendo a desigualdade do acesso qualificado aos serviços. Essa constatação indicou o foco de ação da regulação assistencial, por meio da implantação da RCR: diminuir essas desigualdades, a partir da organização do fluxo dos pacientes à luz de critérios pactuados, tendo por referência o perfil do serviço de saúde existente e o desejado, na perspectiva de prover melhor atendimento aos cidadãos, em tempo eficaz, mesmo em contextos de escassez de recursos, procurando otimizar a utilização da capacidade instalada no município, na região e no estado.

Nesta etapa, inicia-se instalação de equipamentos-servidores e software de banco de dados com capacidade para as diversas funcionalidades previstas no modelo original do AmIS pari passu a definição do modelo de gestão da regulação assistencial (e da RCR): cogestão das esferas estadual e municipal, por região do estado. Em relação à gestão da RCR, ficou assim pactuado: a coordenação geral é do secretário de estado de saúde, que delega essa função para o Cisa/SES, concomitante ao exercício da coordenação do AmIS, por meio do qual se operacionaliza a Rede. 
Os secretários municipais coordenam em seus municípios e participam das decisões referidas à região na qual se inserem, tais como: indicação do coordenador da Central de Regulação Regional (e a do município do Rio), modelagem da rede assistencial, pactuação dos protocolos de regulação por canal de atenção, definição do perfil da equipe das unidades assistenciais e instituições de pesquisa e ensino a serem incorporadas. As questões técnico-operacionais são debatidas no âmbito do Fórum de Coordenadores das Centrais de Regulação em reuniões mensais, sob coordenação do Cisa/SES-RJ, que passa a ser vinculado diretamente ao secretário de estado de saúde.

Mesmo em estágio inicial, o AmIS forneceu a estrutura de base de dados necessária aos estudos de fluxo dos pacientes e do perfil da capacidade instalada, úteis para o desenho da RCR. Nessa etapa, foi elaborado novo diagnóstico por região do estado, agora contemplando: a) estrutura etária e de gênero da população, com sua densidade demográfica e principais características geográficas e de prevalência dos problemas de saúde; b) localização, perfil, porte e produção das unidades de saúde existentes por região; c) análise da demanda reprimida por procedimento/serviço; d) rede de transporte coletivo existente e de ambulâncias postas a serviço da regulação, e demais problemas de acessibilidade; e) definição dos municípios-polo para localização das Centrais de Regulação (CR) regionais e a do município do Rio de Janeiro; f) fluxos assistenciais, de acordo com a complexidade da rede instalada, por canais de atenção.

Em função do déficit de pessoal com perfil adequado para atuar na RCR funcionando 24 horas, sete dias por semana, a SES/RJ realizou concurso público (em 2001) com previsão de 349 vagas para servidores, distribuídas nas seguintes categorias: médicos reguladores, agentes administrativos operadores (videofonistas), suporte de informática e especialistas em saúde pública. Este quantitativo não foi alcançado, incorporando-se então servidores cedidos ou contratados pelas secretarias municipais de saúde (SMS) ou consórcios de saúde das regiões.

Definiram-se, também, os níveis de acesso às informações por tipo de usuário e pelo que a equipe de um município pode 'ver' de outro município, por exemplo. Criaram-se produtos (relatórios, indicadores, telas), extraídos a partir do AmIS, nos mais variados formatos e periodicidade para os diversos setores da SES/RJ, para as SMS e instâncias da RCR, destacando-se os seguintes sistemas de informações: Sistema de Informação de Regulação (Sisreg), implantado nas centrais de regulação; o Sistema de Informatização Hospitalar (Hospub), para os hospitais estaduais, ambos os software públicos, desenvolvidos pelo Datasus/MS; o SIH/SUS; o Sinasc; e SIM.

Esta primeira etapa se caracterizou pelo planejamento e pela pactuação dos princípios e concepção do modelo de regulação em saúde a ser adotado, do modelo de ambiente de informações a ser utilizado, da plataforma computacional e de telecomunicação, do perfil da equipe profissional e da infraestrutura necessária. As CR regionais se interligavam, via Internet, através da Rede Estadual de Informações em Saúde/Centro de Tecnologia da Informação e Comunicação do Estado do Rio de Janeiro (Proderj), utilizando nos equipamentos-servidores plataforma Linux (software livre) com o Cisa/SES/RJ, enfren- 
tando sérios embates por esta escolha. A CR localizada no município do Rio de Janeiro foi a única que utilizou a versão Sisreg-WEB do Datasus.

Ao término do primeiro ciclo dessa experiência, a RCR/RJ estava com a composição que perduraria até dezembro de 2006, qual seja: oito CR regionais, abrangendo todas as regiões do estado, uma central municipal vinculada ao município do Rio de Janeiro e uma central estadual dedicada somente à regulação das internações neonatais e de gestantes de alto risco, conforme o mapa a seguir (Figura 2).

Figura 2 - Rede de CR do estado. Rio de Janeiro - 1999-2006

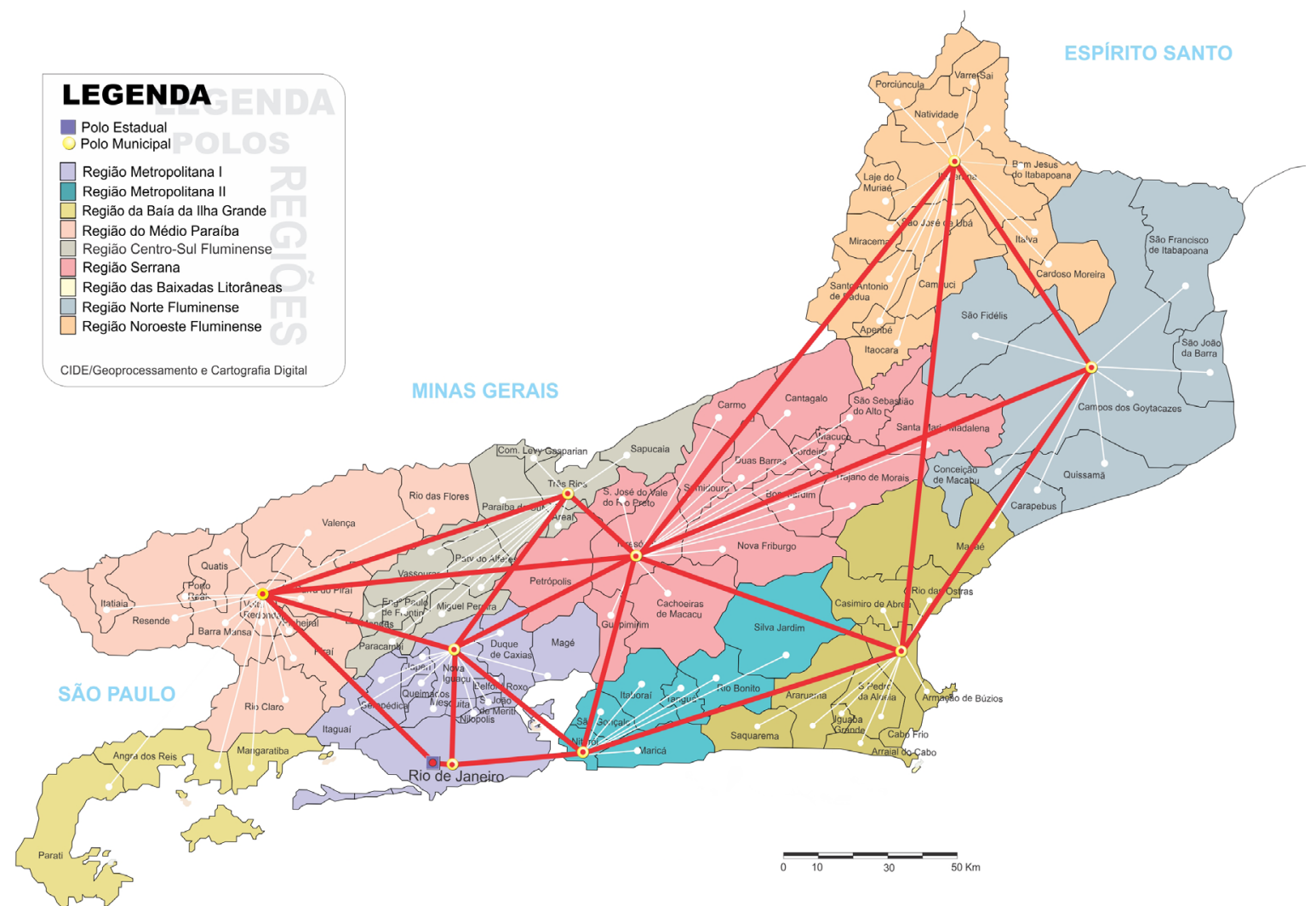

Fonte: Cisa/RJ (2006).

A segunda etapa (2003-2006) concentrou-se na implementação de estratégias que fortaleceram a incorporação de novas práticas regulatórias e de uso da informação na práxis do SUS/RJ, procurando expandir, tanto em termos quantitativo quanto qualitativo, o fluxo de pacientes sob regulação. Nesta direção, pode-se identificar a adoção de cinco estratégias que se complementam.

1. EXPANSÃo ESPACIAL DO EFETIVO FUNCIONAMENTO DAS CR

Inclusão dos municípios em cada uma das regiões que ainda não tinham aderido aos processos de regulação, apesar de pactuados. 
2. Constituição do Arcabouço Jurídico-Institucional da Regulação Assistencial NO ESTADO

Diante de constantes mudanças na gestão das SMS e das unidades assistenciais (UA), bem como do não cumprimento por todos dos pactos estabelecidos, identificou-se a necessidade de maior formalização do processo de regulação assistencial. Fruto dessa estratégia foi a pactuação da resolução SES-RJ n. 2.102, de 14 de julho de 2003 (Estado do Rio de Janeiro/SES, 2003), que definiu a 'missão da RCR-RJ' como sendo: "(...) agilizar e qualificar o fluxo de acesso do cidadão aos serviços e ações de alta e média complexidade em saúde, de forma organizada, colocando-se a serviço da defesa do direito à saúde”.

\section{Expansão dA REGULAC̣ÃO POR CANAIS DE ATENÇÃO}

A expansão ocorreu a partir da incorporação escalonada de leitos/internações por especialidade (Estado do Rio de Janeiro, 2005a). Com os protocolos de regulação (incluindo a ordenação dos fluxos assistenciais dos pacientes) pactuados por região, este processo se deu de forma gradual, por consenso entre os envolvidos. Essa estratégia caracterizou-se por um intenso ciclo de reuniões técnicas com as chefias e equipes dos serviços clínicos e das enfermarias das UA, com os responsáveis pelos canais de atenção dos municípios, sob a coordenação de seus pares estaduais, com o staff diretivo dos municípios, com os secretários municipais de saúde e docentes de instituições acadêmicas. O Quadro 1 apresenta a síntese dessas pactuações.

Quadro 1 - Canais de atenção prioritários e respectivas metas de regulação assistencial

\begin{tabular}{|c|c|}
\hline $\begin{array}{l}\text { CANAIS DE } \\
\text { ATENÇÃO/REGİ̃O }\end{array}$ & Metas de acordo com a Deliberação CIB n. 203/2005 \\
\hline \multicolumn{2}{|c|}{ ATENÇÃO MATERNA INFANTIL E OBSTÉTRICA } \\
\hline Município do Rio & $\begin{array}{l}\text { 50\% das internações realizadas através de processo regulado } \\
100 \% \text { das internações realizadas informadas à CR }\end{array}$ \\
\hline Metropolitana 1 & $\begin{array}{l}\text { 50\% das internações realizadas através de processo regulado } \\
100 \% \text { das internações realizadas informadas à CR da região }\end{array}$ \\
\hline \multicolumn{2}{|c|}{ ATENÇC̄̃O MATERNO-INFANTIL E OBSTÉTRICA DE ALTO RISCO E UTI NEONATAL } \\
\hline Estado do RJ & $100 \%$ das internações realizadas através de processo regulado \\
\hline \multicolumn{2}{|c|}{ ATENÇ̃̃o MATERNO-INFANTIL - PEDIATRIA CLÍNICA (INTERNAÇÃO) } \\
\hline Município do Rio & $\begin{array}{l}\text { 50\% das internações realizadas através de processo regulado } \\
100 \% \text { das internações realizadas informadas à CR }\end{array}$ \\
\hline \multicolumn{2}{|c|}{ ATENÇÃO HEMATOLÓGICA - INTERNAÇÕES E CONSULTAS DE $1^{\underline{A}}$ VEZ } \\
\hline Município do Rio & $\begin{array}{l}50 \% \text { das internações e consultas de } 1^{\underline{a}} \text { vez: através de processo regulado } \\
100 \% \text { das internações realizadas informadas à CR }\end{array}$ \\
\hline Demais regiões & $\begin{array}{l}100 \% \text { internações e consultas de } 1^{\underline{a}} \text { vez realizadas através de processo } \\
\text { regulado }\end{array}$ \\
\hline \multicolumn{2}{|c|}{ SAÚDE MENTAL - INTERNAÇÕES PSIQUIÁTRICAS } \\
\hline Estado do RJ & $\begin{array}{l}\text { 50\% das internações realizadas através de processo regulado } \\
100 \% \text { das internações realizadas informadas à CR }\end{array}$ \\
\hline
\end{tabular}


Quadro 1 - Canais de atenção prioritários e respectivas metas de regulação assistencial (Cont.)

\begin{tabular}{|l|l|}
\hline $\begin{array}{l}\text { CANAIS DE } \\
\text { ATENÇÃO/REGIÃO }\end{array}$ & METAS DE ACORDO COM A DELIBERAÇÃO CIB N. 203/2005 \\
\hline SAÚdE AUDITIVA & $100 \%$ dos procedimentos realizados através de processo regulado \\
\hline Estado do RJ & $\begin{array}{l}50 \% \text { das internações realizadas através de processo regulado } \\
50 \% \text { das internações realizadas informadas à CR }\end{array}$ \\
\hline CLÍnICA MÉDICA & Município do Rio \\
\hline REDE DE ALTA COMPLEXIDADE \\
\hline Metropolitana 2 & $\begin{array}{l}40 \% \text { das internações realizadas através de processo regulado } \\
60 \% \text { das internações realizadas informadas à CR }\end{array}$ \\
\hline
\end{tabular}

Fonte: Estado do Rio de Janeiro (2005a).

\section{Constituição do núCleo interno de REGULAĈ̣̃o}

Foi formado um núcleo interno de regulação em cada unidade hospitalar pública das três esferas de governo (Estado do Rio de Janeiro, 2005b). Esta implantação foi proposta como estratégia de capilarização das ações regulatórias diante das dificuldades de incorporação de práticas regulatórias e de uso da informação na cultura institucional das UA, com as atribuiç̃ões de:

- implementar gestão clínica voltada para a otimização do uso do leito/serviços e para o aumento da qualidade da assistência, a partir do consenso interno estabelecido;

- disponibilizar leito com tecnologia apropriada à necessidade do paciente, considerando os critérios pactuados e respeitando o vínculo do paciente com o serviço hospitalar;

- participar da construção e avaliação dos protocolos de regulação afetos ao hospital;

- avaliar e acompanhar os motivos de retardo de ocupação e desocupação de leitos, provendo a direção com informações relevantes e monitorando o censo diário;

- fazer a interlocução com a CR de referência, garantindo o fluxo da informação e das internações, inclusive do Cadastro Nacional de Estabelecimentos de Saúde (CNES);

- semear a 'cultura da regulação' no interior do hospital.

O fluxo de regulação em sua articulação com a RCR, apresentado na Figura 3, representa um esforço de síntese dessas estratégias.

Os hospitais compõem a parte mais capilarizada da regulação assistencial, articulados no ciberespaço pelo AmIS por meio da implantação do Hospub, o que inclui infraestrutura para Intranet, Extranet e Internet. O modelo lógico da rede de telecomunicação foi construído em conjunto com a equipe de cada hospital, de acordo com o fluxo e processo de trabalho, viabilizando, aos gestores de nível central, funcionalidade de monitoramento desses hospitais à distância, em tempo real, bem como acesso às CR, a critério da direção 
de cada hospital. Ao término desta segunda etapa, 13 unidades hospitalares estaduais estavam com os seguintes módulos do Hospub implantados: farmácia, almoxarifado, emergência, internação, serviço de arquivo médico (Same) e gerência hospitalar. Em quatro desses, também foram instalados serviço de pronto atendimento (SPA), centro cirúrgico, laboratório e ambulatório.

\section{FORMAÇÃO DA EQUIPE TÉCNICA}

Com importantes lacunas na formação dos profissionais servidores da SES e das SMS, foram implementados cursos com uma grade programática diversificada, envolvendo diferentes instituições de ensino localizadas no estado: Pontifícia Universidade Católica do Rio de Janeiro (PUC/RJ), Instituto Alberto Luiz Coimbra de Pós-Graduação e Pesquisa em Engenharia da Universidade Federal do Rio de Janeiro (Coppe/UFRJ), Núcleo de Computação Eletrônica/UFRJ (NCE/UFRJ), Departamento de Informática do Sistema Único de Saúde (Datasus/MS), Serviço Nacional de Aprendizagem Industrial (Senai) e Ensp/Fiocruz. A depender do curso, utilizou-se a modalidade presencial ou de educação a distância, oferecendo-se os seguintes conteúdos: processo de gestão e TI em saúde (totalmente via Internet); Tabwin e TabNet; HTML; geoprocessamento; Epi Info; Java; administração de rede com uso de Linux (software livre); codificação de causa básica (CID) para o SIM e SIH; regulação assistencial; informatização hospitalar, com ênfase nas funcionalidades do (Hospub).

Figura 3 - Responsabilidade gestora e fluxo da regulação assistencial

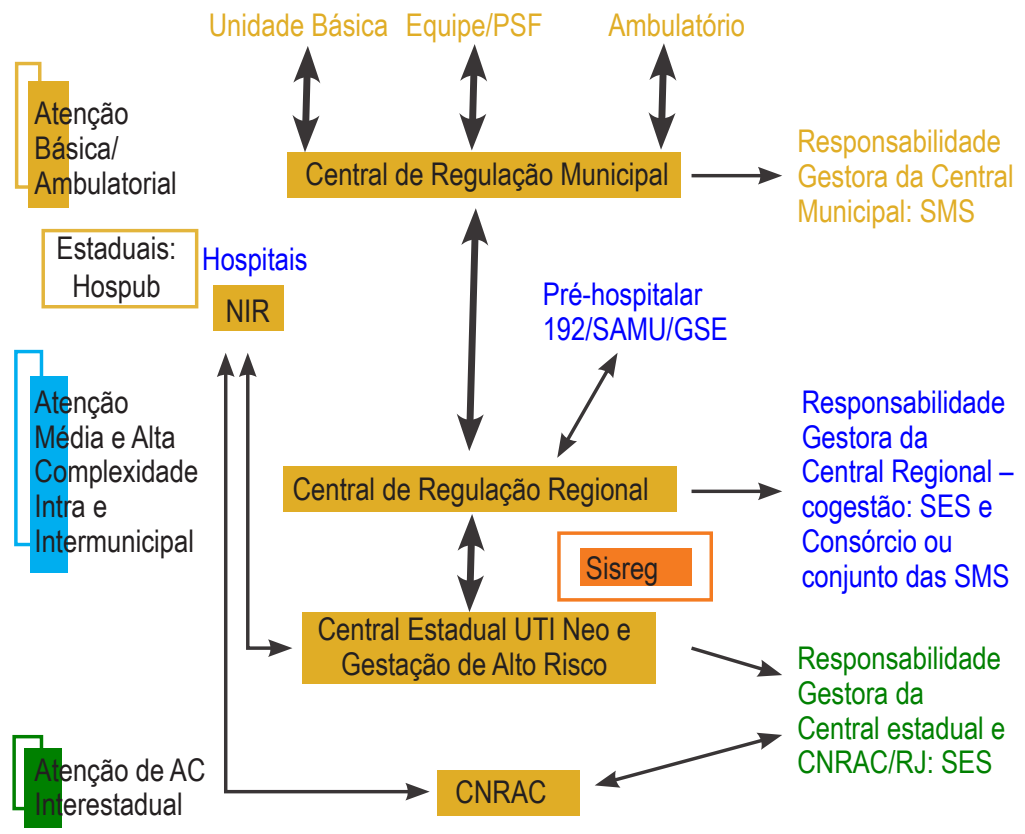

Fonte: Estado do Rio de Janeiro (2005a), atas da CIB/RJ e do Fórum de Coordenadores das CR no período de 1999- 2006. 


\section{Principais Resultados da Análise}

A principal questão evidenciada pela análise refere-se às diferenças entre os pactos estabelecidos, expressos nos documentos que compõem o arcabouço jurídico-institucional, e os resultados efetivamente alcançados. A distância entre 'intenção' e 'gesto', como diz o poeta Chico Buarque de Holanda, caracteriza a situação investigada. Reflexo da distância entre o "SUS que queremos e o SUS que temos"?

Os resultados confirmam a complexidade que envolve a adoção de inovações, principalmente quando pressupõem mudanças em processos consolidados de gestão em saúde, com impacto em estruturas de micropoderes. Esta constatação alerta que implantar o AmIS significa enfrentar limites e desafios cuja matriz explicativa enraízase na própria gênese da organização do setor saúde. A qualidade, grau e velocidade de incorporação de ações informacionais à gestão e ao processo de trabalho em saúde são funções tanto da superação de históricos desafios/limites quanto da emergência de novos. Alguns desses são discutidos a seguir, tendo por referência os fundamentos do AmIS e o entendimento de que a gestão das ações informacionais em saúde constitui macrofunção estratégica do SUS.

\section{Desafio/Limite 1: Hegemonia da lógica fragmentadora na práxis em saúde}

A adoção de práticas intersetoriais e do diálogo transdisciplinar não caracteriza a atual práxis em saúde, na qual prevalece a fragmentação, a setorialização, a departamentalização, com processos decisórios atomizados e estanques, expressão do modo como o Estado brasileiro responde às demandas da sociedade (Castells, 1999; Gómez, 2001; Moraes, 2002). A superação desses limitantes precisa se dar por 'camadas', tendo por referência o aude sapere - 'o ousar saber' kantiano que, em Michel Foucault (1984), corresponde a um processo coletivo de problematização do presente - a 'atualidade' histórica - que liga a atual gestão em saúde às raízes genealógicas de constituição dos dispositivos de Estado e de Ciência \& Tecnologia.

A formação histórica do setor saúde determina uma cultura institucional distante de uma dinâmica de trabalho/atendimento calcada na integração (Ayres, 2009), na articulação, na constituição de uma 'rede' assistencial. Os resultados encontrados evidenciam esta realidade no ERJ, onde a lógica fragmentada e fragmentadora em seus métodos e técnicas de explicação e intervenção se expressa nas UA e nas estruturas das SMS e da SES.

Essa constatação põe em discussão o conceito de regionalização e hierarquização de uma rede assistencial. $O$ princípio da regionalização acumula significativa produção de conhecimento, mas esbarra em desafios políticos e técnico-operacionais a demandarem aprofundamento. Superar estes limites é fundamental para a qualificação da gestão em saúde, como também para iniciativas de implantação do AmIS. Afinal, um de seus fundamentos é a ideia de 'rede', no tempo/espaço virtual, o que contribui para a adoção de ações solidárias e de compartilhamento de conhecimento e de responsabilidades. 
São as ações solidárias e de compartilhamento de conhecimento e de responsabilidades que se tornam, então, práticas políticas que significam a instituição de um poder público coletivo (Espinosa, 1997), cujo pré-requisito é a decisão política de compartilhamento do exercício de poder, algo que está sendo cultivado nos mecanismos coletivos de gestão do SUS, mas não se encontra preponderante no cotidiano institucional, expresso em suas ações rotineiras.

\section{Desafio/Limite 2: A quem interessa o uso da informação em saúde nos processos decisórios em saúde? De quem são os leitos do SUS?}

A análise do fluxo de relatórios, indicadores e de outros produtos/saídas do AmIS confirma a distância entre intenção e gesto. $O$ esforço institucional não se refletiu em ampliação do uso da informação, nem na gestão, nem no processo de trabalho em saúde, que variou no tempo e no espaço-usuário, dentre os seguintes setores: planejamento; atenção básica/Programa Saúde da Família (PSF); vigilância epidemiológica; vigilância sanitária; gerência de assistência à saúde, controle e avaliação; programação pactuada e integrada (PPI); programas assistenciais específicos (tuberculose, hanseníase, atenção à saúde da mulher e da criança).

O estudo em torno da tríade 'usuário da informação' x 'conteúdo informacional' x 'periodicidade de acesso' evidencia intensa flutuação, não permitindo extrair-se um padrão de comportamento de uso dos produtos/saídas do AmIS. O resultado desta análise suscitou a primeira pergunta apresentada anteriormente. Ao cotejá-lo com os relatórios da observação participante, ficam evidentes as coincidências com momentos de crise, de conflito entre áreas técnicas, mudanças de chefias, greves, epidemia de um determinado agravo (por exemplo, dengue). Tal resultado confirma um dos fundamentos do AmIS: sua relação de dependência do contexto institucional e, por conseguinte, do processo de trabalho e de decisão. Serve de alerta para futuras iniciativas de adoção do AmIS, no sentido da imperiosa necessidade do estabelecimento de estratégias que, sem desvinculá-lo do processo de trabalho e de decisão, minimizem sua vulnerabilidade a conjunturas instáveis.

O AmIS constitui no tempo/espaço virtual uma rede de novos dispositivos de governança colocados a serviço dos gestores. Quem se beneficia com esses dispositivos? A população usuária de ações e de serviços de saúde qualificados, efetivos e distribuídos com equanimidade. Mas, a quem interessa uma população usuária atendida com qualidade, efetividade e equanimidade? Aos gestores de saúde? Caso a resposta seja afirmativa, surge a pergunta: por que o uso da informação pelos gestores não se torna sistemático?

Ao longo dos oito anos estudados, a análise do perfil dos interlocutores envolvidos demonstra que estes não se transformaram em usuários intensivos da informação. A investigação identificou os seguintes interlocutores: SES (através de diferentes setores), Cosems/ RJ, SMS (tanto gestores quanto coordenações dos canais de atenção), coordenadores e equipes das CR componentes da RCR/RJ, comissão metropolitana do ERJ, direções, chefias de clínicas / especialidades/serviços e núcleo interno de regulação das unidades 
hospitalares (UH) públicas, das três esferas de governo. A participação nas discussões não se traduziu em gestos/ações que expressem novas práticas e saberes decorrentes da incorporação de ações informacionais na gestão e no processo de trabalho.

Um indicativo de tal realidade encontra-se na fragilidade do processo de uso e atualização, em tempo real, das informações no âmbito do AmIS, questão nevrálgica para os fluxos regulados dos pacientes no estado. Uma explicação para este resultado pode ser encontrada na história institucional das UA. Estas se constituíram de forma atomizada, tornando-se 'ilhas' em busca de excelência. Essa racionalidade se reproduz para o interior dos hospitais, onde cada especialidade (enfermaria) conforma um espaço de micropoder das lideranças médicas que se organizam ao seu redor. Essa práxis é oposta a propostas de organização de 'rede assistencial regulada', que têm como pressuposto a 'abertura desses espaços de micropoderes' e o rompimento com a opacidade das 'razões de Estado'.

A hipótese suscitada é que a 'cultura institucional' torna-se um obstáculo para adesão do corpo técnico dos estabelecimentos de saúde (onde são geradas e registradas as informações) a processos que tornem transparentes seus fluxos internos de admissão e alta, uma vez que a estrutura do AmIS pressupõe acesso aos dados via Internet e/ou Intranet. Mesmo sem estar implementado em toda a sua potencialidade, o AmIS confere transparência à dinâmica cotidiana de trabalho e da assistência ofertada, possibilitando que seja submetida a um crivo mais amplo, como o dos CS.

É nesse contexto - transparência propiciada pelo AmIS - que surge o debate político sobre quem define e como são definidos os critérios dos fluxos assistenciais. Dito de outra forma: 'de quem são os leitos do SUS?' Do chefe da enfermaria/do serviço? Do diretor clínico do hospital? Do médico regulador? Da população adstrita ao hospital, segundo aplicação dos protocolos de regulação pactuados?

Ações informacionais são pré-requisitos para 'fazer regulação em saúde': a partir da gestão qualificada da informação, com uso intensivo de TI, direcionada para o monitoramento da oferta de serviços de saúde, em um determinado território, em um específico tempo, viabilizando que a CR seja o elemento catalisador das informações sobre a situação, mais próxima do real possível, da disponibilidade de recursos adequados para o acolhimento dos pacientes, no tempo eficaz, à luz dos protocolos de regulação. Para isso, faz-se necessário que as UA mantenham, com a CR da região, contínuo fluxo de informações sobre o status de seus leitos, por exemplo.

A estratégia adotada de interlocução, gradualidade e construção coletiva com os envolvidos, inclusive com o Conselho Regional de Medicina do Estado do Rio de Janeiro (Cremerj), não se mostrou suficiente para a adesão a um processo que pressupõe transparência das informações com o objetivo de clarificar o processo de trabalho instituído. $\mathrm{O}$ discurso vigente afirma que os 'os leitos do SUS são do paciente'. Entretanto, observou-se intenso espaço de disputas em torno do profissional que está investido da autoridade de decisão sobre quem entra e sai dos leitos. Historicamente construído em torno das chefias das enfermarias, esse espaço de micropoder resiste a critérios, mesmo pactuados, voltados 
para um atendimento equânime aos cidadãos. Observou-se também resistências no âmbito de estruturas centrais da SES e de algumas SMS.

A dificuldade de manutenção das informações próxima ao tempo real, necessária à regulação assistencial, encontra outro limitante: diante da escassez de oferta de serviços, em alguns canais de atenção, observa-se que os municípios de menor porte (menor capacidade instalada e de 'poder de barganha política') aderem com rapidez aos processos regulados, mantendo atualizadas as informações. Mas, os de maior porte não priorizam a adoção de novas práticas, pois, além do necessário compartilhamento da capacidade instalada do município-polo, as novas práticas são traduzidas pela burocracia local como 'mais uma tarefa' e não como ações que contribuirão para agilizar e qualificar o próprio processo de trabalho.

\section{Desafio/Limite 3: Função Estratégica para o SUS dependente de terceirização}

Ao considerar a gestão das ações informacionais em saúde como macrofunção estratégica do SUS, a opção pela terceirização, mantida pela SES/RJ, de funções essenciais da gestão das informações (por exemplo, as de regulação assistencial), mostrou-se como uma das causas de atrasos e de perda de qualidade em todo o processo de inovação tecnológica. Agrega-se embate em torno da adoção de software público x software proprietário a partir da produção de conhecimento coletivo x privatização do conhecimento institucional. Diante de um processo de construção coletiva, no qual diferentes sujeitos históricos - gestores, profissionais, pesquisadores, conselheiros de saúde - contribuem para a modelagem e melhoria das funções do AmIS, como lidar com movimentos de apropriação dessa expertise coletiva por uma determinada empresa, que passa a oferecer no mercado da saúde 'novas soluções de informática'?

A situação de dependência das estruturas de informação das gestões estaduais agrava-se diante de legislação vigente na maioria dos estados brasileiros, que define o provimento de cargo de analista de sistema e profissões correlatas privativas das empresas estaduais de processamento de dados. Em função dessa legislação, o Cisa/SES-RJ foi impedido de incluir, no concurso público de 2001, profissionais oriundos de campos de saberes fundamentais para a conformação do AmIS.

A análise das atas de reuniões da plenária do Conass e de sua Câmara Técnica de Informação e Informática em Saúde identificou dois outros problemas: baixos salários, acarretando pouca procura por concurso para provimento desses cargos; ausência de uma consistente formação permanente da equipe técnica. Apesar de 6.822 profissionais em todo o estado, de 2003 a 2006, terem participado de capacitação, observou-se significativa rotatividade dessa força de trabalho egressa que, tão logo adquiriam alguma formação específica, competiam no mercado por melhores salários, abandonando o setor público.

Tal realidade agrava e consolida a dependência a empresas, tornando vulnerável a gestão do SUS, sua autonomia, bem como a privacidade dos cidadãos usuários dos serviços 
de saúde. Esta tendência crescente avança pari passu ao sucateamento das instâncias públicas de gestão das ações informacionais em saúde. Dois exemplos ilustram esta tendência:

- Por que a versão web do Sisreg/Datasus, até dezembro de 2006 em teste no município do Rio de Janeiro, não tem seu aperfeiçoamento priorizado pelo Datasus, que opta por 'procurar no mercado uma solução melhor'?

- Por que a implantação do Hospub nos hospitais públicos ficou restrita às $\mathrm{UH}$, dificultando processo articulado de rede assistencial, independente da esfera de governo? Mesmo nas UH estaduais, observou-se pouco engajamento de suas chefias na utilização de funcionalidades do Hospub, especialmente as de gerenciamento hospitalar e as que permitem transparência ao controle do almoxarifado e farmácia, por exemplo.

\section{Desafio/Limite 4: Qual a compreensão dos partícipes da experiência sobre AmIS e regulação assistencial no SUS?}

O modelo do AmIS pressupõe que este seja fruto do pacto estabelecido entre os envolvidos, o que inclui o próprio entendimento em torno do escopo de sua atuação e significado em determinado contexto histórico. Entretanto, tendo por referência a análise do material estudado, observou-se que não foram amplamente apropriados pelo conjunto do SUS/RJ nem o entendimento do AmIS, nem o processo de regulação assistencial.

Ocorreram frequentes relatos/reivindicações de gestores e diretores de estabelecimentos de saúde que reduziam o debate da informação em saúde a questões específicas de determinado SIS, reafirmando sua fragmentação, e de TI em saúde, como distribuição de computadores e acesso à Internet.

A implementação do AmIS, nos moldes dessa experiência (imbricada à regulação em saúde), traduz novos saberes e práticas voltados para o desenvolvimento da capacidade de governança dos gestores do SUS. A inovação não se refere apenas ao AmIS, mas também à regulação assistencial, que, neste caso, se diferencia da lógica de controle e avaliação dos recursos existentes. A regulação assistencial passa a constituir um novo mecanismo de qualificação e fortalecimento da gestão do SUS, com sua atuação ocorrendo pré-factum e não pós-factum. Ou seja, a regulação se dá antes da efetivação de determinados procedimentos de saúde, ao analisar, à luz dos protocolos de regulação pactuados, qual a intervenção mais adequada ao atendimento da demanda. A equipe técnica diretamente envolvida na regulação atua como 'advogada de defesa' dos interesses/necessidades dos usuários do SUS, não decidindo a partir da 'existência de teto financeiro ou de AIH disponível', como acontece no âmbito do controle e avaliação em várias SMS e SES, onde um dos legados da racionalidade do extinto Instituto Nacional de Assistência Médica da Previdência Social (Inamps) refere-se à autorização de procedimentos, pelo médico-supervisor, segundo a disponibilidade financeira.

É importante destacar que não há consenso em torno deste entendimento. O Ministério da Saúde defendia, à época, maior proximidade entre regulação e controle-avaliação, 
que conformariam uma tríade ao incluir-se a auditoria. Já a SES/RJ defendia que regulação assistencial tem por pressuposto defender o direito do cidadão/paciente de receber o atendimento necessário, 'de acordo com os protocolos de regulação pactuados', independente da existência de 'teto orçamentário/financeiro/de AIH', por exemplo, tendo por referência o texto constitucional que garante o direito universal à saúde.

A regulação assistencial implementada nesta experiência afirmava que a disponibilidade financeira pode e deve ser um critério utilizado pelo controle-avaliação, mas não no escopo de protocolos de regulação, portanto, não estando incluído nas atribuições de médicos-reguladores. Estes devem ater-se a analisar a situação clínica do paciente e, em interlocução com o médico-assistente, estabelecer o melhor fluxo para o atendimento resolutivo. Aliar a função de médico-supervisor a de médico-regulador pode caracterizar um 'conflito de interesses' (do paciente em ser atendido e do gestor em não ultrapassar sua disponibilidade financeira), dificultando que o médico-regulador exerça em plenitude seu papel: defender o interesse do paciente, para além de uma concepção racionalizadora. Nesta situação, a análise da disponibilidade de recursos financeiros da SES e/ou SMS permanece única e exclusivamente como atribuição das estruturas de controle e avaliação.

\section{Desafio/Limite 5: Pactos estabelecidos - a distância entre intenção e gesto}

Em vários momentos, observou-se que, com a substituição de um secretário municipal de saúde, seu sucessor quer inaugurar 'o novo', como se o marco zero coincidisse com sua entrada na gestão da saúde. Essa racionalidade impregna a prática política brasileira e confunde o debate entre as conquistas inerentes à alternância de poder, nos marcos da democracia representativa.

As mudanças, tanto de titulares da pasta quanto de seu staff diretivo, acarretaram interrupções significativas na logística técnica-operacional da regulação assistencial, por conseguinte nos avanços do AmIS no estado. As alterações impõem novas 'rodadas de negociação' para a continuidade dos pactos estabelecidos. A busca pelo alcance da continuidade dos pactos gerou vários conflitos nas regiões do estado, resistências e contradições nos encaminhamentos. As forças políticas vinculadas ao SUS/RJ oscilaram entre resistência aberta à iniciativa ou descrença e apoio entusiástico ou cauteloso ("É bom demais para ser verdade! É uma utopia!" - depoimento de uma secretária municipal de saúde em reunião da CIB-RJ, 2005).

Tendo como pressuposto que a realização de procedimentos regulados pode ser um indicativo do comprometimento dos gestores com os pactos expressos nas resoluções e deliberações da CIB-RJ, analisa-se, em abordagem quantitativa, os procedimentos realizados, à luz dos protocolos de regulação, intermediados pelo AmIS. A Tabela 1 apresenta a proporção de internações reguladas/informadas no total das internações realizadas, por região, do primeiro semestre de 2004 ao primeiro semestre de 2006.

Observa-se um avanço da regulação assistencial no ERJ ao se analisar o aumento gradual no número de internações reguladas/informadas. Retirando-se o município do Rio 
de Janeiro, observam-se os seguintes percentuais para o estado: $23,2 \%$ em 2004; $29,7 \%$ em 2005; 38,1\% apenas no primeiro semestre de 2006.

Desde o início do processo, o município do Rio de Janeiro apresentou percentuais muito abaixo da expectativa. Esse desempenho impactou nos percentuais totais do estado. Cabe destacar a diferença dos valores quando se desagregam por canais de atenção. Por exemplo, a psiquiatria superou a meta definida, alcançando, no primeiro semestre de 2006, 100\% das internações nas seguintes regiões: Metropolitana 1 e 2, Baixada Litorânea, Centro-Sul Fluminense e município do Rio de Janeiro. No entanto, quanto às internações classificadas como da rede de alta complexidade e clínica médica, instalada nos grandes municípios, houve pouco avanço.

Tabela 1 - Percentual regulado/informado de internações/SUS no estado. Rio de Janeiro - 2004-2006

\begin{tabular}{|c|c|c|c|c|c|}
\hline \multirow{2}{*}{ REGIÕES } & \multicolumn{2}{|c|}{2004} & \multicolumn{2}{|c|}{2005} & \multirow{2}{*}{$\frac{2006}{1 \text { ○ SEMESTRE }}$} \\
\hline & 1을estre & $2 \cong$ SEMESTRE & 1 ○ SEMESTRE & 2 SEMESTRE & \\
\hline Baía Ilha Grande & 0.3 & 31.6 & 12.3 & 26.1 & 66.9 \\
\hline Baixada Litorânea & 1.85 & 1.2 & 0.6 & 1.5 & 0.6 \\
\hline $\begin{array}{l}\text { Centro-Sul } \\
\text { Fluminense }\end{array}$ & 9.1 & 23.5 & 37.2 & 84.7 & 58.5 \\
\hline Médio Paraíba & 30.4 & 45.3 & 34.6 & 54.7 & 60.5 \\
\hline Metropolitana 1 & 31.8 & 30.1 & 31.6 & 24.6 & 30.0 \\
\hline Metropolitana 2 & 4.4 & 5.4 & 9.7 & 10.7 & 12.5 \\
\hline Noroeste Fluminense & 0 & 0 & 3.9 & 49.6 & 94.8 \\
\hline Norte Fluminense & 36.5 & 52.3 & 75.4 & 67.3 & 74.0 \\
\hline Serrana & 11.5 & 23.9 & 18.8 & 24.5 & 26.3 \\
\hline Total Parcial & 17.1 & 24.8 & 25.6 & 34.0 & 38.1 \\
\hline Rio de Janeiro & 2.4 & 2.8 & 0.5 & * & 8.0 \\
\hline TOTAL & 13.9 & 20.1 & 20.3 & 28.1 & 27.6 \\
\hline
\end{tabular}

* Não se dispõe das informações referentes ao $2^{\circ}$ semestre de 2005 no município do Rio de Janeiro. Fonte: SIH (Base SES/RJ/2004-2006) e Sisreg (Base das diversas regiões).

O valor próximo a 30\% não significa, por si só, que essas internações ocorreram com a agilidade e qualidade necessárias. A lógica de utilizar o número de internações como indicativo retrata tão somente expansão no acesso regulado, não permitindo nenhuma outra inferência. Existe uma lacuna na estrutura dos dados do AmIS desenvolvido na SES/RJ, indicando a necessidade de novos formatos de informações que permitam um monitoramento contínuo do processo de trabalho em saúde e em torno dos resultados alcançados, como ação incorporada ao cotidiano da gestão em saúde.

Destaca-se, por exemplo, a não adoção, dentre os relatórios de rotina, de indicadores que permitam o monitoramento da 'fila de espera' dos pacientes e seu follow up, em termos 
de agravamento, por exemplo, pela demora no atendimento, ou mesmo pelo não atendimento. A não publicização desse monitoramento, principalmente para os CS, representa uma opção política que contribui para a manutenção desse status quo. Incluir no AmIS a perspectiva desse monitoramento na rotina dos serviços de saúde não é suficiente, mas com certeza é necessário para que se possa subsidiar uma nova prática, para além de uma lógica contábil e de produção historicamente construída.

Da análise do discurso e de seu arcabouço normativo-institucional, extrai-se a intenção do alcance da atenção integral, da melhoria da gestão do SUS/RJ e dos serviços de saúde calcados na integralidade, regionalização, hierarquização e qualidade. O problema é: no período estudado, persistiu uma distância entre a plena realização da 'intenção' e a concretude do 'gesto', ou seja, sua materialização efetiva no real. $O$ estudo do rastreamento das internações (totais e reguladas) evidenciou que o fluxo assistencial não se mostrou compatível com as deliberações, resoluções e os próprios protocolos de regulação pactuados.

\section{Discussão e Considerações Finais}

Depreende-se dos resultados que o SUS/RJ não incorporou, em larga escala, as ações informacionais vinculadas ao processo da regulação assistencial como estratégia de ampliação de seus dispositivos de governança. A análise do longo processo de implementação do AmIS no ERJ evidencia que este é um desafio complexo, que só avança com a efetiva decisão política dos envolvidos, tanto das esferas decisórias quanto das técnico-

-operacionais. É preciso que todos se comprometam e participem, ou seja, é um desafio dos componentes do SUS.

A investigação da aplicação desse modelo teórico em uma situação concreta, articulada à implementação da regulação assistencial em saúde, pelo período de oito anos, produziu resultados que permitem responder às duas questões iniciais, quais sejam:

- Contribuiu para uma gestão direcionada à incorporação das ações informacionais nos processos decisórios em saúde? Em termos.

- Forneceu subsídios para o aprimoramento do modelo original de AmIS, colaborando para a melhoria de sua aplicação em outras iniciativas de gestão estadual no SUS? Sim.

A análise evidenciou que o debate em torno da gestão das ações informacionais em saúde foi intensificado no decorrer do período pari passu à implantação do AmIS. Ocorreram avanços gerenciais, incorporação de inovações, capacitações, produção de saberes e práticas novas no intercampo da informação e TI em saúde, em dupla direção: nas instituições de ensino e pesquisa envolvidas e nos serviços de saúde. Antigos e novos problemas foram enfrentados. No entanto, os benefícios para a população são encobertos diante da magnitude e de dimensões ainda não suficientemente compreendidas. Ao final de oito anos, encontrar percentuais em torno de $30 \%$ de internações reguladas face o total de internações que continuaram acontecendo de forma casuística, independente do 
perfil da demanda e da oferta dos serviços de saúde e à revelia dos protocolos de regulação pactuados, sinaliza um contexto que precisa continuar sendo investigado.

É um equívoco supor que as 'soluções' se encontram no AmIS em saúde in per si, em uma postura tecnocrática e tecnicista. Essas 'soluções', ao transcenderem o escopo do AmIS, transbordam para o contexto da regulação assistencial, e deste para o contexto da construção histórica da tríade saúde/doença/cuidado, inserida na formação política, social e econômica brasileira. Talvez esta constatação, enriquecida pela citação de Chauí no início deste capítulo, seja a principal contribuição da iniciativa do SUS/RJ a outras experiências de gestão estadual: evidenciar a necessidade de uma compreensão rigorosa do contexto, no qual está sendo adotado o AmIS e com isso desvendar caminhos a serem trilhados para o enfrentamento de limites/desafios, não única e exclusivamente em seu âmbito.

Afinal, o desafio/limite 1 da lógica fragmentada e fragmentadora caracteriza o Estado brasileiro que atua não a partir de uma ação global, permanente e transparente, mas de forma essencialmente reativa e tópica, respondendo a 'crises localizadas'.

Em relação ao desafio/limite 2, Moraes (2002) demonstrou que, na vida contemporânea, cada vez mais coexistem superinformação e subinformação, abundância e escassez de informação, em um processo de intensa transparência da sociedade para o Estado, mas de opacidade do Estado para a sociedade. Neste contexto, como podem se consolidar dispositivos, como o AmIS, voltados para a transparência das 'razões e ações do Estado'? Afinal, a quem interessa o uso da informação nos processos decisórios? O legado do recente período autoritário (golpe militar de 1964), no qual 'informação é uma questão de segurança nacional', agravou ainda mais a percepção de ameaça aos micropoderes consolidados diante de dispositivos que confiram transparência ao funcionamento das instituições. Estas se sentem 'vulneráveis' ao exercício do controle social.

As discussões decorrentes da implantação do AmIS vinculado à regulação assistencial desvendaram, de forma inquestionável, o jogo de poderes que se efetiva em torno do controle dos leitos do SUS. Ocorre uma defesa acirrada da manutenção de um status quo no qual impera a opacidade sobre a situação real da ocupação dos leitos, sobre quem está de fato investido da 'autoridade' de decidir sobre quem é internado e a partir de quais critérios.

A implantação de mecanismos que confiram transparência a critérios orientadores do fluxo assistencial, rompendo com clientelismos e casuísmos nesta dinâmica cotidiana, não é um desafio apenas para a gestão das ações informacionais. Como conseguir apoio para uma iniciativa que defende a incorporação, na cultura institucional, do princípio de que as informações fornecidas pelo cidadão são dele e não da instituição, da equipe ou do médico? Poder efetivar a resposta de que as informações em saúde e os leitos do SUS são 'do cidadão' é um desafio para o SUS, onde está inclusa a atuação dos conselheiros de saúde. Duas frases ilustram a dimensão deste desafio/limite 2: "Os governos não gostam das informações, porque elas lhes retiram liberdade e capacidade discricionária” (Lord John Maynard Keynes). "Eu não tenho escrúpulos: o que é bom a gente fatura, o que é ruim a gente esconde" (ministro de Estado da Fazenda Rubens Ricupero, em conversa com o 
jornalista Carlos Monforte, 1994. O sinal do link via satélite que transmitiria a entrevista já estava aberto, e os lares cujas antenas parabólicas estavam sintonizadas no canal privativo de satélite da Rede Globo captaram a conversa informal).

O estudo das atas das reuniões de instâncias nacionais do SUS evidencia o predomínio de formulações que restringem o debate em torno da informação a tecnicalidades computacionais, confinando-o a aspectos pontuais, com baixa capacidade de mudanças, esvaziando o processo de (re)pensar as informações e a TI em saúde. A opção dos gestores por processos de terceirização de ações informacionais enfraquece a capacidade de intervenção da gestão pública em saúde. Torna o exercício desta função estratégica para o SUS dependente de um mercado empresarial poderoso (desafio/limite 3).

Ao fragmentar a 'busca de soluções' a partir de contratação, no mercado, de diferentes 'pacotes informacionais' e/ou softwares houses, perde-se a possibilidade da apropriação do desenvolvimento informacional como parte integrante da inteligência pública em saúde. Apesar de não explicitado no discurso, subjaz uma concepção de externalidade das ações informacionais à própria práxis da saúde. $\mathrm{O}$ entendimento majoritário encontrado nos documentos estudados caracteriza as práticas e saberes da informação em saúde como fora da ação finalística da saúde, caminhando em sentido contrário à evidência de sua crescente incorporação ao processo do cuidado em saúde.

A 'política real' de informação e informática em saúde também utiliza, como justificativa para a terceirização, a opção por uma política de fomento e incremento do mercado/setor produtivo da TI e informação. De fato, observa-se uma atualização, no intercampo da informação em saúde, de embates históricos da sociedade brasileira em torno do papel do setor público e do setor privado. É anterior ao SUS a luta por uma política que priorize investimentos nas instituições e serviços públicos, onde o setor privado participe de forma complementar.

Os investimentos realizados são focais, atomizados, não obedecem a padronizações abertas e são estruturados de forma isolada, seja entre esferas de governo, seja dentro da mesma esfera, agravando a situação, cada vez mais comum, de aprisionamento (lock-in) de entidades públicas às empresas vencedoras das licitações com suas 'soluções tecnológicas proprietárias'. Em nome do fortalecimento dessas empresas, de seu business intelligent - BI privado -, observa-se uma ausência sistemática de incremento ao desenvolvimento do 'BI público’ pari passu ao sucateamento de espaços públicos de gestão da informação e TI em saúde, acarretando importantes lacunas de saberes e práticas para a melhoria da saúde principalmente em situações que a dinâmica empresarial não vislumbre como promissor -, havendo uma similitude nesta racionalidade à encontrada no âmbito das doenças negligenciadas pelas empresas produtoras de medicamentos, por exemplo.

A proposta de organização do AmIS se constitui em um amplo processo de aprendizagem coletiva, com práticas calcadas na solidariedade, no compartilhamento de responsabilidades, de circulação de ideias e saberes envolvendo instituições acadêmicas e de serviços de saúde, apontando caminhos profícuos de inovações. Implantar modelos de gestão da informação e TI em saúde não pode ser traduzido/reduzido a ir ao mercado e comprar uma 'solução de informática' prêt-à-porter. 
O fortalecimento da gestão pública das ações informacionais enfrenta importantes interesses privados que lutam tanto para se tornarem perenes quanto para se apropriarem da produção de conhecimento institucional gerado coletivamente pelos parceiros do SUS, incorporando-os a 'seus novos produtos' ofertados ao próprio SUS. As instituições de saúde se apresentam fragilizadas nas negociações de prorrogação/renovação de contratos em face de sua pouca autonomia, expertise e equipe constituída em seu interior. Estabelecem-se, entre a esfera pública e os interesses privados, relações nas quais as fronteiras se diluem, tornam-se tênues: se 'desmancham no ar'! É um desafio do Estado e da sociedade brasileira (re)construir o significado de res publica (coisa pública), o compromisso com o 'bem comum', o valor ético atribuído à vida humana, o direito universal à saúde e o papel do setor privado nesta equação.

A introdução de novas práticas em espaços institucionais consolidados gera resistências tanto de 'feudos técnicos' cristalizados em micropoderes quanto dos interesses que se beneficiam com a manutenção do status quo. Diante dessa conjuntura, perde-se a oportunidade de surgimento de novas formas de organização do cuidado/atenção à saúde propiciadas por um desenvolvimento informacional público incorporado ao 'fazer saúde', nos marcos do SUS.

O novo a ser criado não significa, necessariamente, inovações metodológicas e tecnológicas. Em muitos casos, remete a novos conceitos e entendimentos em torno de ações existentes, que passam a ter outras significações e diferentes impactos na práxis em saúde, à medida que o contexto histórico muda. Esta parece ser a situação que envolve a implantação de um ambiente de informações em saúde, bem como da regulação assistencial. Esta questão se mostrou central na dinâmica da experiência estudada (desafio/limite 4): qual a compreensão sobre AmIS e regulação assistencial no SUS?

A cada reunião era necessária nova explanação sobre o que é 'regulação assistencial' e um 'ambiente de informações em saúde'. Cita-se um exemplo emblemático: ao serem perguntados sobre o que entendiam como regulação, a grande maioria dos aprovados no concurso para o cargo de médico-regulador foi clara: "não sei do que se trata!". Este é um desafio para a gestão do AmIS e da regulação assistencial em interlocução com todo o SUS.

A evolução temporal do percentual de internações reguladas vis-à-vis o total de internações evidencia as consequências, para a saúde da população, de situações onde ocorra uma convergência de forças políticas em um determinado tempo/espaço, aumentando-se a probabilidade de cumprimento dos pactos estabelecidos, ou onde ocorram mudanças nesse equilíbrio instável. A execução de pactos políticos confere materialidade à distância entre intenção e gesto (desafio/limite 5). Paim (2008: 319) alerta para a dimensão substantiva desta questão: "um dos maiores desafios colocados no presente, ao lado do financiamento estável, é como assegurar uma autonomia relativa do SUS e das políticas de saúde em relação às interferências partidárias e corporativas”.

A efetivação de uma rede de sistemas e serviços regionalizada, hierarquizada de atenção integral à saúde pressupõe a incorporação na práxis em saúde de transparência das 'razões de Estado' e de seus pactos políticos, bem como da 'ética da solidariedade' 
(Morin, 1997), superando padrões competitivos de relacionamento inter e intra-institucional, com o compartilhamento de espaços e mecanismos técnico-operacionais, como implícito na atualização do AmIS, expressando novas práticas políticas na gestão em saúde. Este é um desafio para o SUS em sua inserção no Estado brasileiro.

A investigação resultou em importantes aportes para o aprimoramento do modelo original de AmIS, contribuindo para a melhoria de sua aplicação em outras iniciativas de gestão estadual no SUS. Há ainda um longo e complexo caminho a ser construído para que o AmIS possa efetivamente ser apropriado como dispositivo que amplia a capacidade de governança dos gestores de saúde e a visibilidade das ações governamentais para o controle social, contribuindo, em toda sua potencialidade, para a (re)organização do sistema de saúde em uma rede regionalizada, hierarquizada, equânime e com qualidade. Neste cenário, o AmIS terá a conformação que expresse a correlação de forças, formada na defesa de seus fundamentos e no compromisso com a transparência das 'razões de Estado', que orientam a política de saúde em espaços/tempo concretos. Utilizar a palavra 'desafio' junto à palavra 'limite' significa perceber o presente carregado de possibilidades voltadas para o fortalecimento do pacto ético da solidariedade na saúde como fundamento para que a sociedade brasileira vivencie o 'encantamento' e a 'esperança' no SUS.

\section{REFERÊNCIAS}

ALMEIDA-FILHO, N. Transdisciplinaridade e o paradigma pós-disciplinar na saúde. Saúde e Sociedade, 14(3): 30-50, 2005.

AYRES, J. R. C. M. Cuidado: trabalho e integração nas práticas de saúde. Rio de Janeiro: IMS/Uerj, Abrasco, 2009.

CAMPOS, G. W. S. Reforma política e sanitária: a sustentabilidade do SUS em questão? Revista Ciência E⿱ Saúde Coletiva, 12(12): 301-306, 2007.

CASTELLS, M. Sociedade em Rede - a era da informação: economia, sociedade, cultura. São Paulo: Paz e Terra, 1999.

CENTRO DE INFORMAÇÕES EM SAÚDE/SECRETARIA DO ESTADO DO RIO DE JANEIRO (Cisa/SES-RJ). Plano de Regulação da Assistência do Estado do Rio de Janeiro 2006 2009. Rio de Janeiro, 2006.

CHAUÍ, M. S. Vida e Obra de Baruch Espinosa. São Paulo: Nova Cultural, 1997. (Coleção Os Pensadores, Espinosa)

DUNLEY, G. A. Festa Tecnológica: o trágico e a crítica da cultura informacional. Rio de Janeiro: Editora Fiocruz, 2005.

ESTADO DO RIO DE JANEIRO. Deliberação da Comissão Intergestores Bipartite - CIB/RJ. Diário Oficial do Estado, Rio de Janeiro, n. 39, 24 jun. 1999.

ESTADO DO RIO DE JANEIRO. Deliberação da Comissão Intergestores Bipartite - CIB/RJ. Diário Oficial do Estado, Rio de Janeiro, n. 203, de 04 nov. 2005a.

ESTADO DO RIO DE JANEIRO. Deliberação da Comissão Intergestores Bipartite - CIB/RJ. Diário Oficial do Estado, Rio de Janeiro, n. 205, de 20 dez. 2005b.

ESTADO DO RIO DE JANEIRO. Secretaria de Estado de Saúde. Resolução SES-RJ, n. 2.102, de 14 jul. 2003. Diário Oficial do Estado, Rio de Janeiro, 2003. 
ESPINOSA, B. Tratado Político. São Paulo: Nova Cultural, 1997. (Coleção Os Pensadores, Espinosa) FOUCAULT, M. O que é o iluminismo? In: RABINOW, P. The Foucault Reader. New York: Pantheon Books, 1984.

GÓMEZ, M. N. G. Para uma reflexão epistemológica acerca da ciência da informação. Perspectivas em Ciência da Informação, 6(1): 5-18, 2001.

KANT, I. Crítica da Razão Pura. São Paulo: Editora Nova Cultural, 1996. (Coleção Os Pensadores)

LEVY, P. As Tecnologias da Inteligência: o futuro do pensamento na era da informática. Rio de Janeiro: Editora 34, 1993.

MINAYO, M. C. S; ASSIS, S. G. \& SOUZA, E. R. (Orgs.). Avaliação por Triangulação de Métodos: abordagem de programas sociais. Rio de Janeiro: Editora Fiocruz, 2005.

MORAES, I. H. S de. Política, Tecnologia e Informação em Saúde: a utopia da emancipação. Salvador: UFBA, Casa da Qualidade, 2002.

MORAES, I. H. S \& GÓMEZ, M. N. G. Informação e informática em saúde: caleidoscópio contemporâneo da saúde. Revista Ciência E⿱ Saúde Coletiva, 12(3): 550-551, 2007. Disponível em: <www.cienciaesaudecoletiva.com.br>. Acesso em: 09 maio. 2010.

MORAES, I. H. S \& VASCONCELLOS, M. M. Política nacional de informação, informática e comunicação em saúde: um pacto a ser construído. Revista Saúde em Debate, 69(29): 86-98, 2005.

MORAES, I. H. S et al. Inclusão digital e conselheiros de saúde: uma política para a redução da desigualdade social no Brasil. Revista Ciência Ë Saúde Coletiva, 14(3): 879-888, 2009.

MORIN, E. Complexidade e ética da solidariedade. In: CASTRO, G.; CARVALHO, E. A. \& ALMEIDA, M. C. (Orgs.). Ensaios de Complexidade. Natal, Porto Alegre: UFRN, Sulina, 1997.

PAIM, J. S. Reforma Sanitária Brasileira: contribuição para a compreensão crítica. Rio de Janeiro: Editora Fiocruz, 2008.

RISI JR., J. B. Rede interagencial de informações para a saúde: dez anos de desenvolvimento. In: MINISTÉRIO DA SAÚDE, OPAS. A Experiência Brasileira em Sistemas de Informação em Saúde. Brasília: Ministério da Saúde, Opas, 2009.

VASCONCELLOS, M. M.; GRIBEL, E. B. \& MORAES, I. H. S. Registros em saúde: avaliação da qualidade do prontuário do paciente na atenção básica, Rio de Janeiro, Brasil. Cadernos de Saúde Pública, 24, supl. 1: S173-S182, 2008.

VASCONCELlOS, M. M.; MORAES, I. H. S \& CAVALCANTE, M. T. L. Política de saúde e potencialidades de uso das tecnologias de informação. Revista Saúde em Debate, 61: 219-235, 2002. 